\title{
Rheumatic heart disease among Omani schoolchildren
}

Aly A. Hasab, 'Ali Jaffer ${ }^{2}$ and Abdulla M. Riyami ${ }^{3}$

$$
\begin{aligned}
& \text { أمر اضر التلب الروماتزمية بين تلاميذ المدارس العُمانينئ }
\end{aligned}
$$

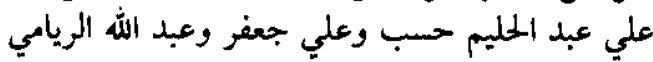

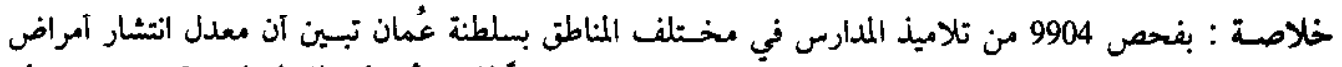

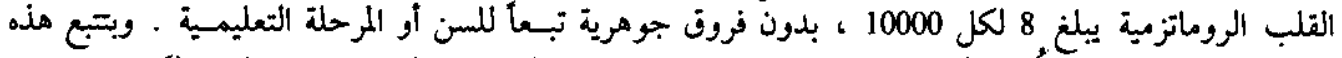

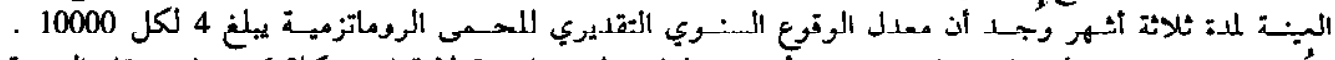

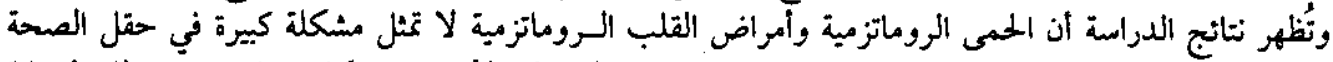

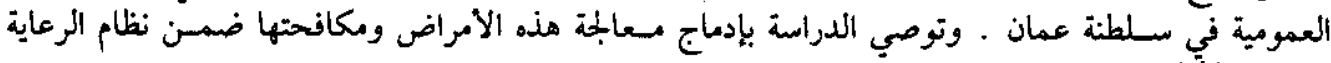

ABSTRACT Screening of 9904 Omani schoolchildren from different regions in Oman gave a prevalence rate of rheumatic heart disease of 8 per 10000 with no significant difference by sex or level of education. Follow-up of the sample for three months gave an estimated annual incidence of rheumatic fever of 4 per 10000 . The positive predictive value of definite murmurs for diagnosis of cardiovascular disease was $35.21 \%$ for school health physiclans and $86.67 \%$ for reglonal physicians. The results show that rheumatic fever and rheumatic heart disease are not major public health problems in Oman. The study recommends integration of the management and control of the disoasos within the primary health care eystem.

\section{Les cardiopathies mumatismales chez les écoliers omanais}

RESUME L'examen clinique de 9904 écoliers omanais originaires de différentes régions du pays a révélé un taux de prévalence des cardiopathies rhumatismales de 8 pour 10000 avec aucune différence significative entre les deux sexes ou les différents niveaux d'éducation. Le suivi de l'échantillon sur une période de trois mois a indiqué une incidence annuelle estimative du rhumatisme articulaire aigu de 4 pour 10000 . La valeur prédictive positive des souffles confirmés pour établir le diagnostic de maladie cardio-vasculaire s'élevait ả $35,21 \%$ pour les médecins scolaires et à $86,67 \%$ pour les médecins régionaux. Les résultats indiquent que le thumatisme articulaire aigu et les cardiopathies rhumatismales ne constituent pas des problèmes majeurs de santé publique à Oman. L'étude recommande l'intégration de la prise en charge des cas et de la lutte contre ces affections dans le système des soins de santé primaires.

'Professor of Epidemiology, High Institute of Public Health, Alexandria University, Alexandria, Egypt. ${ }^{2}$ Director-General, Health Affairs, Ministry of Health, Muscat, Oman.

"Head, Meditino Department, Royal Hospital, Ministry of Hearth, Muscat, Oman.

Received 22/07/96; accepled 24/09/96. 


\section{Introduction}

Rheumatic fever and theumatic heart disease are major causes of death and disability in developing countries. Rheumatic heart disease is the most common form of heart disease and accounts for over $30 \%$ of all cardiac patients admitted to hospital. It is also the main cause of death in the first four to five decades of life $[1,2]$. Today, the disease has almost disappeared in industrialized countries. Prevalence rates in different countries are difficult to compare because of differences in the ages of the populations studied and in the methodologies of the surveys. Nevertheless, a mean prevalence rate of 10 per 1000 for the age group 5-19 years can be taken as a reasonable and convenient approximation for planning purposes in countries where data are not available [1]. Rates recorded in schoolchildren range from a low level to as high as 33 per $1000[1,3,4]$. The screening of children for theumatic heart disease and the creation of a registry for the cases detected are essential components of a rheumatic fever prevention programme [4]. This study was carried out with the aim of determining the prevalence of rheumatic heart disease among Omani schoolchildren aged 6-18 years, estimating the incidence of rheumatic fever among the study population and studying some epidemiological factors related to the occurrence of these diseases

\section{Subjects and methods}

The study used a cross-sectional approach for rheumatic heart disease with a followup for rheumatic fever. It was carried out on a representative sample of Omani schoolchildren selected by a multistage stratified random procedure. The sample of 10000 schoolchildren was drawn from the eight regions in Oman according to the total number of students in each region. The first stage sampling was selection of the schools from the list provided by the Ministry of Education. The second and final stage was selection of the students within each school.

Basic data such as age, sex, name of the school, address and level of education were collected. Clinical examination to detect the presence of any murmur was performed by trained health physicians. Children with murmurs were referred to the regional hospitals for their opinion and, once verified, they were referred to the Royal Hospital for echocardiography and other investigations required to confirm the diagnosis. The study sample was followed up for three months from the date of examination for evidence of rheumatic fever. Jones criteria were used for the diagnosis of rheumatic fever [1].

\section{Results}

The total sample amounted to 9904 Omani schoolchildren, $4412(44.5 \%)$ of them males and 5492 temales. The mean age of the studied sample was $12.8 \pm 3.63$ years; $13.3 \pm 3.76$ years for males and $12.4 \pm 3.42$ years for females. More than half of the sample $(50.8 \%)$ were in primary school, about one-third (32.3\%) in preparatory school and $16.8 \%$ at secondary school.

Of the 9904 children screened, eight cases of theumatic heart disease were identified (three mitral stenosis, four mitral regurgitation and one pulmonary stenosis), a rate of 8.08 per $10000 ; 9.07$ per 10000 for males and 7.28 for females, with no statistically significant difference (Table 1 ).

Only one rheumatic fever case was discovered during the three-month follow-up 
period, giving an annual incidence of $\mathbf{4 . 0}$ per 10000 . Females had more congenital heart disease ( 30.95 per 10000 ) than males $(6.80$ per 10000$)$. This difference is statistically significant (Fisher exact $P$ value $=$ 0.005 ). The common defects were ventricular septal defect $(45 \%)$ and pulmonary stenosis $(10 \%)$. Cardiac manifestations of congenital heart disease were noted in the survey. Their prevalence relative to that of rheumatic heart disease is shown in Table 1. There was no significant difference between school levels regarding rheumatic heart disease and congenital heart disease (Table 2). Assessment of the efficiency of murmurs as a screening test for detection of cardiovascular diseases showed that it has a positive predictive value of $15.47 \%$ for school health physicians, as out of 181 students referred, 28 cases were diagnosed (Table 3). The value was $2.73 \%$ ( 3 out of 110 ) for suspected murmurs and $35.21 \%$ ( 25 out of 71 ) for definite murmurs. The positive predictive value of murmurs diagnosed by regional physicians was $62.22 \%$, as out of 45 cases referred by regional phy-

Table I Prevalence rate of cardiovascular diseases per 10000 Omani schoolchildren by sex, 1992-1993

\begin{tabular}{|c|c|c|c|c|c|c|c|}
\hline \multirow[t]{3}{*}{ Sex } & \multirow{3}{*}{$\begin{array}{l}\text { Number of } \\
\text { students } \\
\text { examined }\end{array}$} & \multicolumn{6}{|c|}{ Cardiovascular disease" } \\
\hline & & \multicolumn{2}{|c|}{$\begin{array}{c}\text { Rheumatic } \\
\text { heart disease }\end{array}$} & \multicolumn{2}{|c|}{$\begin{array}{c}\text { Congenital } \\
\text { heart disease }\end{array}$} & \multicolumn{2}{|c|}{ Total } \\
\hline & & No. & Rate & No. & Rate & No. & Rate \\
\hline Males & 4412 & 4 & 0.07 & 3 & 6.80 & 7 & 15.87 \\
\hline Females & 5492 & 4 & 7.28 & 17 & 30.95 & 21 & 38.24 \\
\hline Total & 9904 & 8 & 8.08 & 20 & 20.19 & 28 & 28.27 \\
\hline
\end{tabular}

$x^{2}=4.32 ; P=0.037$

Fisher exact $P$ value $=0.512$

'Fisher exact $P$ value $=0.005$

Table 2 Prevalence rate of cardiovascular dlseases per 10000 Omani schoolchildren by level of education, 1992-1993

\begin{tabular}{|c|c|c|c|c|c|c|c|}
\hline \multirow[t]{3}{*}{ Level } & \multirow{3}{*}{$\begin{array}{l}\text { Number of } \\
\text { students } \\
\text { examined }\end{array}$} & \multicolumn{6}{|c|}{ Cardiovascular disease* } \\
\hline & & \multicolumn{2}{|c|}{$\begin{array}{c}\text { Rheumatic } \\
\text { heart disease }\end{array}$} & \multicolumn{2}{|c|}{$\begin{array}{c}\text { Congenital } \\
\text { heart disease }\end{array}$} & \multicolumn{2}{|c|}{ Total } \\
\hline & & No. & Rate & No. & Rate & No. & Rate \\
\hline Primary & 5034 & 4 & 7.95 & 4 & 17.95 & 13 & 25.82 \\
\hline Preparatory & 3201 & 3 & 9.37 & 10 & 31.24 & 13 & 40.61 \\
\hline Secondary & 1669 & 1 & 6.00 & 1 & 6.00 & 2 & 12.00 \\
\hline Total & 9904 & 8 & 8.07 & 20 & 20.19 & 28 & 28.27 \\
\hline
\end{tabular}

" $\chi^{2}$ between primary versus preparatory and secondary $=0.22 ; P=0.641$

$b$ Fiehor exeot $\mathrm{P}$ value -0.618

${ }^{c} \chi^{2}=0.27 ; P=0.602$ 
Table 3 Efficiency of murmurs for detectlon of rheumatic heart disease among Omani schoolchildren, 1992-1993

\begin{tabular}{|c|c|c|c|c|c|}
\hline \multicolumn{2}{|c|}{ School health physiclan } & \multicolumn{2}{|c|}{ Reglonal physician } & \multicolumn{2}{|c|}{ Final diagnosis } \\
\hline Normal & 9724 & & & & \\
\hline \multirow[t]{3}{*}{ Suspected } & 110 & Normal & 98 & & \\
\hline & & Suspected & 7 & $\begin{array}{l}\text { Normal } \\
\text { AHD } \\
\text { CHD }\end{array}$ & $\begin{array}{l}7 \\
- \\
-\end{array}$ \\
\hline & & Definite & 5 & $\begin{array}{l}\text { Normal } \\
\text { RHD } \\
\text { CHD }\end{array}$ & $\begin{array}{l}2 \\
1 \\
2\end{array}$ \\
\hline \multirow[t]{2}{*}{ Definite } & 71 & Normal & 38 & & \\
\hline & & Suspected & 8 & $\begin{array}{l}\text { Normal } \\
\text { RHD } \\
\text { CHD }\end{array}$ & $\begin{array}{l}6 \\
- \\
2\end{array}$ \\
\hline \multirow[t]{2}{*}{ Total } & gona & Total & 181 & Total & 45 \\
\hline & & $\begin{array}{l}\text { Normal } \\
\text { Suspected } \\
\text { Dofinite }\end{array}$ & $\begin{array}{r}136 \\
15 \\
30\end{array}$ & $\begin{array}{l}\text { Normal } \\
\text { RHD } \\
\text { CHD }\end{array}$ & $\begin{array}{r}17 \\
8 \\
20\end{array}$ \\
\hline
\end{tabular}

$\chi^{2}$ for definite murmers $=22.34: P=0.00002$

sicians to the Royal Hospital in Muscat, 28 cases were diagnosed as cardiovascular disease. The value was $13.33 \%$ ( 2 out of 15 ) for suspected murmurs and $86.67 \%$ (26 out of 30 ) for definite murmurs. There was a significant difference in the positive predictive value of definite murmurs between school health physicians and regional physicians $\left(\chi^{2}=22.34 ; P=0.00002\right)$.

\section{Discussion}

Rheumatic fever and rheumatic heart disease are the most common cardiovascular diseases in children and young adults. In the past 50 years, they have emerged as major contributors to cardiovascular disease morbidity and remain a major public health problem in developing countries [510]. There are approximately 10 million cases of rheumatic fever and rheumatic heart disease in the world, with an estimated 60000 children and young adults dying annually from rheumatic heart disease. They are typically associated with poverty, in particular with poor housing and overcrowding, both of which favour the spread of upper respiratory tract infection [9]. The most striking feature of the global epidemiology of rheumatic fever and rheumatic heart disease is the contrast between their progressive decline in industrialized countries and their continuing intensity in the developing world. Today, the mean annual incidence of rheumatic fever in affluent communities is less than 5 per 100000 schoolchildren and it is still falling [II]. As a result, the prevalence of rheumatic heart disease in these communities has shown an equally dramatic decline; among children it is now about $0.1-0.5$ per $1000[1,12]$. This 
trend was triggered and has been maintained by improvement in socioeconomic conditions and general living standards. The benefits of improved medical care and the introduction of antimicrobial agents came later and contributed to the accelerated decline in the incidence of rheumatic fever. However, the recent resurgence of rheumatic fever in middle-class families in some parts of the industrialized world has highlighted the fact that, even in such countries, there has been no decrease in the incidence of group A streptococcal throat infections and the potential for rheumatic fever still remains [13]. This fact has important implications for rheumatic fever control programmes in many countries.

The association between group A $\beta$-haemolytic streptococcal upper respiratory tract infection and the subsequent development of acute rheumatic fever has been established $[7,9,13,14]$ However, despite the efforts of clinicians. epidemiologists and laboratory scientists, the pathogenic mechanisms leading to the development of rheumatic fever remain unknown. It has been postulated that there are particular serotypes of group A streptococci that are rheumatogenic. However, data to support this hypothesis of selective potential rheumatogenicity are, at present, only epidemiological.

The prevalence of rheumatic heart disease detected in this study (8.1 per 10000 ) is approaching that in industrialized countries. Rapid socioeconomic development in Oman, accompanied by proliferation of educational establishments, hospitals and other medical facilities, and improved sanitation, have led to a reduction in communicable diseases. In 1993, infectious and parasitic diseases constituted only $9.7 \%$ of all hospital discharges, with a rate of 10.8 per 10000 population [16].
According to the World Health Organization (WHO) preprogramme pilot study report for 16 collaborating countries for the prevention of rheumatic fever and rheumatic heart disease, the global average prevalence rate of rheumatic heart disease was 2.2 per 1000 (range between 0.1 and 12.6) [17]. It was higher in the African and Eastern Mediterranean Regions (4.7 and 4.4 per 1000 respectively). The countries with the highest prevalence rates were Zambia (12.6), Sudan (10.2), Bolivia (7.9) and Egypt (5.1). The percentage of recently identified cases was higher in the Eastern Mediterranean (8.1). In the Medina district of Saudi Arabia the prevalence of rheumatic heart disease among schoolchildren aged 6-15 years was 2.4 per 1000 [18]:

With regard to rheumatic fever, the estimated incidence rate found in the study (4.0 per 10000$)$ is also lower than that reported from the Islamic Republic of Iran (8 per 10000$)$ or Sri Lanka $(14.3$ per $10000)$. From 1977 to 1981 , the incidence of acute rheumatic fever among white suburhan children in the United States of America (USA) was 0.5 per 100000 . A retrospective review of yearly admissions of acute rheumatic fever in Barbados between 1971 and 1990 showed a declining trend with relative stability since 1986 . The incidence rate of acute rheumatic fever was 9 per 100000 schoolchildren. The incidence rate per 10000 hospital admissions was 20 in 1971 and has remained low (3) since $1986[I I]$. However, it must be remembered that in developing countries most studies of rheumatic fever and rheumatic heart disease have been hospital-based. Few studies covering whole communities have used the revised Jones criteria. Techniques for confirming the diagnosis, such as echocardiography, have only become available since the $1980 \mathrm{~s}$. 
The insignificant difference in the prevalence of rheumatic heart disease by sex and educational level observed in this study is in agreement with that reported in India [3]. Studies in Saudi Arabia and Sudan have reported higher rates of rheumatic heart disease among females [4].

The positive predictive value of clinical examination as a screening test for detection of rheumatic heart disease was in agreement with that reported in India and Saudi Arabia [18,19].

The reported prevalence of congenital heart disease (20.19 per 10000$)$ in this study was lower than that reported among Delhi schoolchildren (3.2 per 1000) in India [20] and in pupils in Denmark (6.1 per 1000). The prevalence of congenital heart disease at birth in Oman is 2 per 1000 live births [21]. The percentage of ventricular septal defects reported in the study is higher than that reported in the USA and England [22].

\section{Conclusions and} recommendations

The results of the national rheumatic heart disease survey show that the prevalence rate of the disease in Oman is approaching that of industrialized countries. There is no need for a national programme for the prevention and control of this disease. Management and control activities for both rheumatic fever and rheumatic heart disease should be within the primary health care system.

\section{Acknowledgements}

The authors thank WHO for the support given in preparing the protocol of the survey and training school health physicians. They gratefully acknowledge the effort made by the school health physicians, regional physicians and the staff of the Cardiology Department of the Royal Hospital in Muscat in implementing the survey.

\section{References}

1. Ahoumatic fovor and rheumatic heart disease. Report on a WHO study group. Geneva, World Health Organization, 1988 (WHO Technical Report Series, No.764).

2. Vijaykumar $\mathbf{M}$ et al. Incidence of rheumatic fever and prevalence of rheumatic heart disease in India. International journal of cardiology, 1994, 43(3): 221-8.

3. Vashistha VM et al. Prevalence of rheumatic heart disease in schoolchildren. Indian paedjatrics, 1993, 30(1):53-6.

4. Ibrahim-Khalil $\mathrm{S}$ et al. An epidemiological survey of theumatic fever and rheumatic heart disease in Sahaia town, Sudan. Journal of epidemiology and community health, 1992, 46(5):477-9.
5. Hasan AM. Acute rheumatic fever. Medicine international, 1993, 491-6.

6. Prevention of rheumatic fever. Aeport of a WHO Expert Committee. Geneva, World Health Organization, 1996 (WHO Technical Report Series, No. 342).

7. Nordet P. News from the World Health Organization Cardiovascular Disease Unit. WHO streptococcal/rheumatic fever newsletter, 1992, 6:1-2.

8. Makowitz M, Kaplan E. Reappearance of rheumatic fever. Advances in pediatrics, $1989,36: 39-66$.

9. Kumar R. Controlling rheumatic heart disease in developing countries. World health forum, 1995, 16(1):47-51. 
10. Dodu SRA, Bothig S. Rheumatic tever and theumatic heart disease in developing countries. Provention. World health forum, 1986, 10:203-12.

11. Noah PK. Trends in acute rheumatic fever. The Barbados experience. Journal of tropical pediatrics, 1994, 40(2):94-6.

12. Venuta $\mathbf{A}$ et al. Aheumatic fever: a retrospective study of a case series of the last 20 years [In Italian]. Pediatria medica $\theta$ chirurgica, 1995, 17(1):37-9

13. Veaocy LG, Tani LY, Hiel HR. Persistence of acute rheumatic fever in the intermountain area of the United States. Journal of pediatrics, 1994, 124(1):9-16

14. Bhave SY et al. Epidemiology of streptococcal infoction with reforence to rheumatic fever. Indian paediatrics, 1991, 28 (12):1503-8.

15. Martin DR et al. Acute meumatic fever in Auckland, New Zealand: spectrum of associated group A streptococci different from oxpootod. Podiatric infoctious dioease journal, 1994, 13(4):264-9.

16. Annual statistical report, 1993. Muscat, Oman, Ministry of Health, 1993.

17. WHO Cardiovascular Diseases Unit and principal investigators. WHO programme for the prevention of rheumatic fever/ theumatic heart diseases in 16 developing countries: report from Phase 1 (1986-90). Bulletin of the World Health Organization, 1992, 70(2):213-18

18. Al-Sekait MA, Al-Sweliem AA, Tahir M. Rheumatic heart disease in schoolchildren in western district, Saudi Arabia. Journal of the Royal Society of Health, 1990, 110:15-19.

19. Shrestha UK, Bhattarai TN, Pandey MR. Prevalence of rheumatic fever and theumatic heart disease in schoolchildren in a rural community of the hill region of Nepal. Indian heart journal, 1980, 72:403-7.

20. Shrestha NK, Padmavati S. Congenital heart disease in Delhi schoolchildren. Indian medical journal, 1980, 72:403-7.

21. Hasab AA. Jaffer A. Congenital anomalies among Omani births. Paper presented at the ICHED, 1996. High Institute of Public Health, Alexandria, Egypt, 1417 October 1995 (In publication, High institute of Public Health bulletin).

22. Dickinson FD. Hampton I. Congenital heart lesions. Medicine international 1993, 457-463 